\title{
PENGGUNAAN ANTIBIOTIK PROFILAKSIS PADA PASIEN BEDAH SESAR (Cesarean section) DI RSUD A.W.S SAMARINDA
}

\author{
Rima Thaharah ${ }^{1}$, Jaka Fadraersada ${ }^{1}$, M Muh Amir ${ }^{2}$ \\ ${ }^{1}$ Laboratorium Penelitian dan Pengembangan Kefarmasian "Farmaka Tropis", \\ Fakultas Farmasi, Universitas Mulawarman, Samarinda \\ *Email :Thaharah.rima@yahoo.com \\ ${ }^{2}$ Program Studi Pendidikan Kimia, Fakultas Keguruan dan Ilmu Pendidikan, \\ Universitas Mulawarman, Samarinda
}

\begin{abstract}
Surgery Fault is a way of born a fetus by making an incision on the wall of uterus through the front wall of abdomen. Nowadays, women prefer the obstetrician and gave birth by the help of an obstetrician because in reality this way made the mortality of infant and women who gave birth can be reduced. WHO reports of 137 countries found that there are 69 countries (50.4\%) who had a cesarean section about $>15 \%$. This study aims to obtain the data about the use of antibiotics in patients with cesarean section in Abdul Wahab Sjahranie Samarinda hospital, seen from the type and the class of antibiotics, route, dose, frequency, duration, time of administration and the rate of the quality from the use of prophylaxis antibiotics in cesarean section patients based on the Gyssens method. This research is a descriptive evaluative research with retrospective data collection in 120 medical records of cesarean section. Data were taken in January and December 2014. The results showed that the majority of cesarean section patients were patients with aged 20-35 years which is amounted to $85.83 \%$, the highest indication is patients with preterm labor at $20 \%$ and is based on the analysis of the quality of antibiotic use with Gyssens method shows the use of antibiotics category IV is 100\%.
\end{abstract}

Key words: cesarean surgery, prophylaxis antibiotics

\begin{abstract}
ABSTRAK
Bedah Sesar adalah suatu cara melahirkan janin dengan membuat sayatan pada dinding uterus melalui dinding depan bagian perut. Wanita pada jaman modern saat ini lebih menyukai ahli kandungan dan melahirkan dengan bantuan ahli kandungan karena dalam kenyataannya dengan cara ini angka kematian bayi dan wanita yang melahirkan dapat ditekan serendah mungkin. WHO melaporkan dari 137 negara ditemukan bahwa terdapat 69 negara $(50,4 \%)$ yang memiliki angka persalinan
\end{abstract}


bedah sesar (Cesarean section) $>15 \%$. Penelitian ini bermaksud untuk mendapatkan data penggunaan antibiotik pada pasien bedah sesar (Cesarean section) di RSUD Abdul wahab Sjahranie Samarinda yang dilihat dari aspek jenis dan golongan antibiotik, rute, dosis, frekuensi, dan waktu pemberian dan menilai kualitas penggunaan antibiotik profilaksis pada pasien bedah sesar (Cesarean section) berdasarkan metode Gyssens. Penelitian ini merupakan penelitian deskriptif evaluative dengan pengambilan data secara retrospektif pada 120 catatan rekam medik pasien bedah sesar. Data yang diambil pada bulan Januari hingga Desember 2014. Hasil penelitian menunjukkan bahwa pasien bedah sesar terbanyak adalah pasien usia 20-35 tahun sebesar $85,83 \%$, pasien dengan indikasi terbanyak adalah persalinan preterm sebesar $20 \%$ dan berdasarkan analisis kualitas penggunaan antibiotik dengan metode Gyssens menunjukkan penggunaan antibiotik kategori IV ialah $100 \%$.

Kata kunci : Bedah sesar, antibiotik profilaksis

\section{PENDAHULUAN}

Salah satu tujuan penggunaan antibiotik profilaksis yang rasional terhadap proses pembedahan adalah untuk mengurangi penggunaan antibiotik yang tidak tepat sehingga dapat di minimalisisr konsekuensi penyalahgunaan antibiotik. Oleh karena itu penelitian mengenai ketepatan penggunaan antibiotik profilaksis pada pasien bedah sesar sangat diperlukan untuk mengetahui ketepatan penggunaan antibiotik profilaksis tersebut dalam mencegah terjadinya infeksi setelah operasi bedah sesar yang dapat dilihat dari aspek jenis dan golongan antibiotik, rute, dosis, frekuensi, dan waktu pemberian.

Wanita pada jaman modern saat ini lebih menyukai ahli kandungan dan melahirkan dengan bantuan ahli kandungan karena dalam kenyataannya dengan cara ini angka kematian bayi dan wanita yang melahirkan dapat ditekan serendah mungkin. Ini adalah perhitungan kasar yang berarti dari perawatan kebidanan. Kaum wanita yang sehat tidak lagi meninggal karena sebab kehamilan ataupun bersalin dan segala sesuatunya dapat dicapai melalui pengetahuan yang lebih luas, fasilitas yang lebih baik, peralatan yang lebih sempurna dan spesialisiasi terus berkembang [1]

Tindakan bedah sesar menunjukkan perkembangan yang semakin meningkat dari tahun ke tahun. WHO melaporkan dari 137 negara ditemukan bahwa terdapat 69 negara $(50,4 \%)$ yang memiliki angka persalinan bedah sesar (Seksio cesarea) $>15 \%$. Angka kejadian perlakuan bedah sesar pada ibu hamil disebabkan karena infeksi luka operasi (ILO) yang merupakan bagian dari infeksi nosocomial dan merupakan masalah dalam pelayanan kesehatan. Pada tahun 2005, WHO melaporkan bahwa ILO terjadi $2,5 \%$ dari 27 juta pasien yang di operasi setiap tahun dan $25 \%$ dari jumlah infeksi terjadi di fasilitas pelayanan [2] 


\section{METODE PENELITIAN}

Metode dari penelitian ini adalah retrospektif yang bersumber dari data rekam medik pasien bedah sesar dengan pendekatan penelitian kualitatif. Kajian penggunaan antibiotik profilaksis pada pasien bedah sesar termasuk non eksperimen tetapi survey atau eksplorasi karena tidak ada perlakuan yang dimanipulasi.

Populasi pada pasien bedah sesar yang menjalani pengobatan di RSUD Abdul Wahab Sjahranie Samarinda berjumlah 767 jiwa, dan sampel yang digunakan ialah 120 jiwa penarikan sampel dilakukan dengan teknik random atau acak.

\section{HASIL DAN PEMBAHASAN}

Distribusi umur pasien bedah sesar di RSUD Abdul Wahab Sjahranie Samarinda Tahun 2014 disajikan dalam Gambar 1.

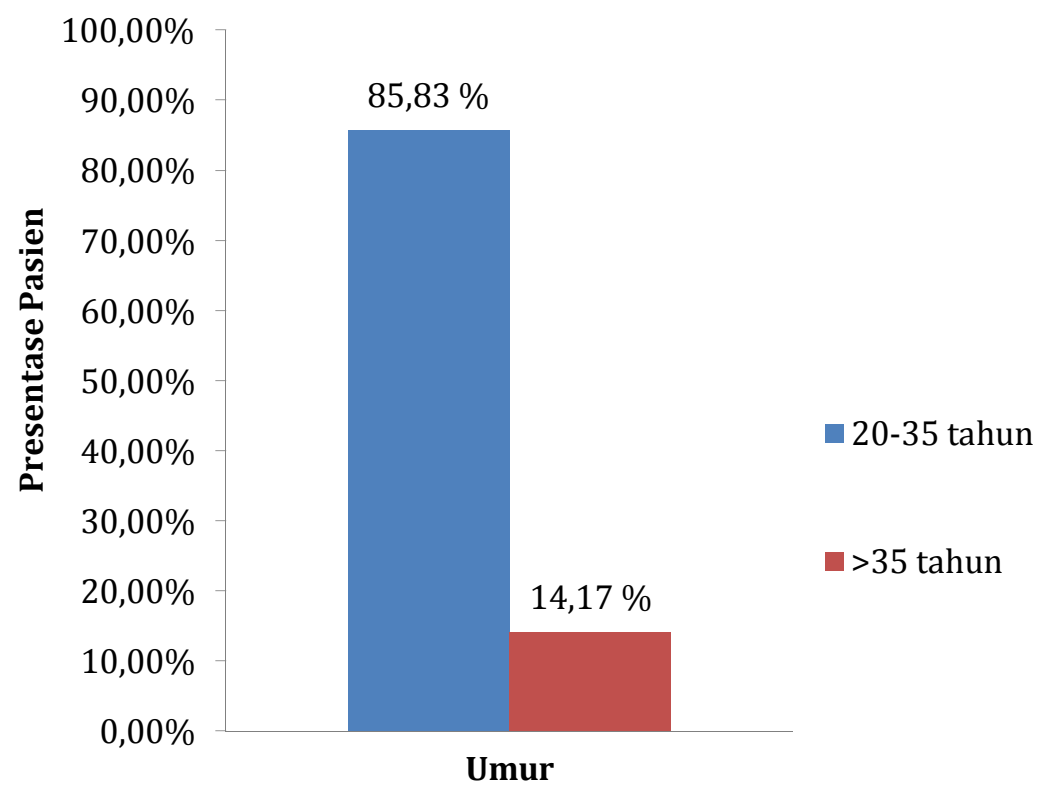

Gambar 1. Distribusi Umur Pasien Bedah Sesar di RSUD Abdul Wahab Sjahranie Samarinda Tahun 2014

Pasien bedah sesar di RSUD Abdul Wahab Sjahranie Samarinda tahun 2014 terbanyak adalah usia 20-35 tahun sebanyak 103 Pasien. Dikarenakan umur juga dapat mempengaruhi proses persalinan, semakin tinggi umur seseorang maka akan beresiko dalam proses persalinan. Menurut [3] dari segi kesehatan ibu yang berumur $<20$ tahun rahim dan panggul belum berkembang dengan baik, begitu sebaliknya yang berumur $>35$ tahun kesehatan dan keadaan rahim tidak sebaik 
seperti saat ibu berusia $20-35$ tahun. Umur ibu $<20$ tahun dan $>35$ tahun merupakan umur yang tidak reproduktif atau umur tersebut termasuk dalam resiko tinggi kehamilan. Umur pada waktu hamil sangat berpengaruh pada kesiapan ibu untuk menerima tanggung jawab sebagai seorang ibu sehingga kualitas sumber daya manusia makin meningkat dan kesiapan untuk menyehatkan generasi penerus dapat terjamin. Kehamilan di usia muda atau remaja dibawah usia 20 tahun akan mengakibatkan rasa takut terhadap kehamilan dan persalinan, hal ini disebabkan pada usia tersebut ibu mungkin belum siap untuk mempunyai anak dan alat- alat reproduksi ibu belum siap untuk hamil. Begitu juga kehamilan di usia tua yaitu diatas 35 tahun akan menimbulkan kecemasan terhadap kehamilan dan persalinan serta alat- alat reproduksi ibu terlalu tua untuk hamil [4]

Distribusi pasien bedah sesar di RSUD Abdul Wahab Sjahranie Samarinda Tahun 2014 berdasarkan indikasi medis disajikan dalam Gambar 2.

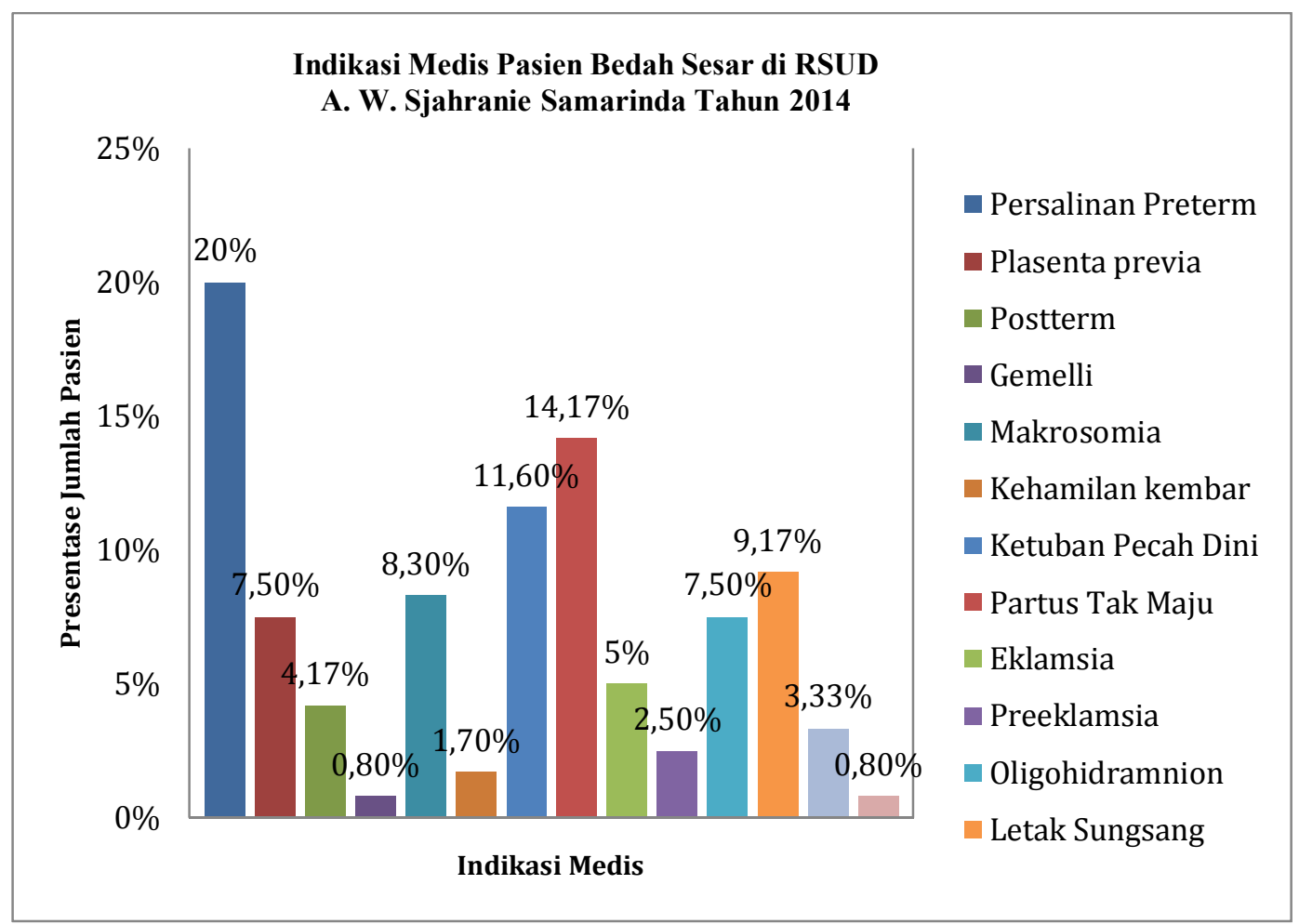

Gambar 2. Distribusi Pasien Bedah Sesar di RSUD Abdul Wahab Sjahranie Samarinda Tahun 2014 Berdasarkan Indikasi Medis

Indikasi medis pasien bedah sesar di RSUD Abdul Wahab Sjahranie Samarinda Tahun 2014 terbanyak adalah persalinan preterm . hal ini dikarenakan persalinan preterm ialah persalinan yang terjadi pada kehamilan kurang dari 37 minggu dengan berat badan lahir kurang dari 2500gr. Yang ditandai dengan kontraksi uterus seperti mau melahirkan sebelum kehamilan aterm. Beberapa faktor resiko ibu yang berhubungan kelahiran preterm yaitu umur yang memiliki resiko 
saat melahirkan adalah dibawah 20 tahun dan diatas 35 tahun, pada wanita yang paritasnya lebih dari 3 ada kecenderungan mempunyai resiko bayi lahir preterm [5]

Tabel 1. Penggunaan Golongan dan Jenis Antibiotik Profilaksis Tunggal di RSUD Abdul Wahab Sjahranie Samarinda Tahun 2014

\begin{tabular}{|c|c|c|c|c|}
\hline \multirow{2}{*}{ No } & \multirow{2}{*}{ Golongan } & \multirow{2}{*}{ Jenis } & \multicolumn{2}{|c|}{ Jumlah } \\
\hline & & & Frekuensi & Persentase \\
\hline 1 & $\begin{array}{l}\text { Sefalosporin } \\
\text { generasi III }\end{array}$ & Sefotaksim & 120 & $100 \%$ \\
\hline \multicolumn{3}{|c|}{ Total } & 120 & $100 \%$ \\
\hline
\end{tabular}

Pasien menerima antibiotik profilaksis terbanyak adalah sefotaksim secara tunggal. Berdasarkan penelitian [6] sefotaksim merupakan golongan sefalosporin generasi ketiga yang berspektrum luas dan peka terhadap gram positif maupun negatif terutama terhadap enterobacteriaceae atau batang gram negatif enterik.. Aktivitas bakterisidal didapat dengan cara menghambat sintesis dinding sel. In vitro sefotaksim memiliki aktivitas luas terhadap bakteri gram positif dan gram negatif. Dapat juga menghambat segala macam bakteri yang terkontaminasi atau bakteri yang ada didalam kulit dan bagian dalam perut. Pemberian antibiotik profilaksis sefotaksim telah sesuai dengan pedoman yang telah ditetapkan dari RSUD Abdul Wahab Sjahranie Samarinda.

Golongan antibiotik yang direkomendasikan untuk bedah ialah pada golongan $\beta$-laktam. Antibiotik $\beta$-laktam adalah antibiotik yang memiliki struktur berupa cincin $\beta$-laktam dan umumnya digunakan untuk mengatasi infeksi bakteri pasca bedah. Antibiotika $\beta$-laktam bekerja dengan menghambat pembentukan peptidoglikan di dinding sel. Beta-laktam akan terikat pada enzim transpeptidase yang berhubungan dengan molekul peptidoglikan bakteri, dan hal ini akan melemahkan dinding sel bakteri ketika membelah [6]

Berdasarkan Pharmacotheraphy Handbook $6^{\text {th }}$ Edition sefazolin adalah sefalosporin generasi pertama yang merupakan first line dari semua tindakan pembedahan. Sefazolin patogen terhadap bakteri gram negatif yaitu Bacilli, anaetobes, grup b streptococci, enterococci. Kelebihan dari sefazolin ialah efek samping yang ringan, dosis rendah, memiliki spektrum yang sempit, efektif melawan bakteri penyebab infeksi luka operasi dan harga yang relatif murah.

Untuk pasien yang memiliki sifat resistensi dengan antibiotik golongan $\beta$ laktam seperti penisilin dan sefalosporin dapat diberikan antibiotik golongan aminoglikosida, dan fluoroquinolon.[7]

Tabel 2. Distribusi Rute Antibiotik di RSUD Abdul Wahab Sjahranie Samarinda Tahun 2014

\begin{tabular}{llll}
\hline No & Golongan & Jenis & Rute \\
\hline 1 & Sefalosporin generasi III & sefotaksim & intravena \\
\hline & Total & & $120(100 \%)$ \\
\hline
\end{tabular}


Berdasarkan rute pemberian antibiotik tabel di atas dapat dilihat bahwa $100 \%$ antibiotik profilaksis diberikan secara intravena. Hal ini telah sesuai dengan teori yang menjelaskan bahwa penggunaan antibiotik profilaksis umumnya diberikan secara intravena yang telah terbukti efektif untuk mencegah infeksi luka operasi setelah operasi dan mencegah terkontaminasi nya alat ketika akan dilakukannya pembedahan. Pemberian secara intravena agar konsentrasi efektif pada jaringan tercapai sebelum pembedahan dimulai.

Tabel 3. Distribusi Pemberian Dosis Antibitoik Profilaksis di RSUD Abdul Wahab Sjahranie Samarinda Tahun 2014

\begin{tabular}{cccc}
\hline No & Golongan & Jenis & Dosis \\
\hline 1 & Sefalosporin generasi III & Sefotaksim & $1 \mathrm{~g}$ dan $2 \mathrm{~g}$ \\
\hline
\end{tabular}

Berdasarkan dosis penggunaan antibiotik pada tabel di atas dapat dilihat bahwa pasien bedah sesar menerima antibiotik dengan dosis yang telah memenuhi ketentuan dosis yang ada pada pedoman penggunaan antibiotik. Pemberian dengan dosis $2 \mathrm{~g}$ digunakan untuk meningkatkan konsentrasi kemampuan daya hambat dari bakteri selama proses operasi berlangsung, namun pada pemberian $1 \mathrm{~g}$ dan $2 \mathrm{~g}$ pun memberikan efek yang sama di dalam tubuh dengan waktu paruh 1-1,5 jam atau tidak lebih dari 24 jam.

Tabel 4. Distribusi Waktu Pemberian Antibiotik Profilaksis di RSUD Abdul Wahab Sjahranie Samarinda Tahun 2014

\begin{tabular}{ccc}
\hline Waktu Pemberian & \multicolumn{2}{c}{ Jumlah } \\
\cline { 2 - 3 } Antibiotik & Frekuensi & Persentase \\
\hline Dosis tunggal $1 \times 1$ hari & 120 & $100 \%$ \\
\hline
\end{tabular}

Berdasarkan waktu pemberian penggunaan antibiotik pada tabel di atas dapat dilihat bahwa penggunaan antibiotik profilaksis pasien bedah sesar telah memenuhi kesesuaian dengan literatur pedoman penggunan antibiotik profilaksis bahwa pada proses pembedahan sesar dosis tunggal sudah cukup untuk memberikan efek. Hal ini dikarenakan pada proses pembedahan sesar memakan kurang lebih 1-2 jam. Jika pembedahan dilakukan dengan waktu yang panjang lebih dari 4 jam diperlukan penambahan dosis antibiotik untuk menjaga konsntrasi efektif antibiotik dalam jaringan, khususnya untuk antibiotik yang memiliki waktu paruh yang singkat. 
Tabel 5. Penggolongan kualitas penggunaan antibiotik profilaksis pada pasien bedah sesar di RSUD Abdul Wahab Sjahranie Samarinda Tahun 2014 Berdasarkan Alur Metode Gyssens

\begin{tabular}{|c|c|c|c|c|c|c|c|c|}
\hline \multirow{2}{*}{ No } & \multirow{2}{*}{ Jenis Antibiotik } & \multicolumn{6}{|c|}{ Kategori } & \multirow{2}{*}{ Total } \\
\hline & & 0 & 1 & 2 & 3 & $4 \mathrm{~A}$ & 5 & \\
\hline \multirow[t]{3}{*}{1} & Sefotaksim & 0 & 0 & 0 & 0 & 120 & 0 & 120 \\
\hline & TOTAL & 0 & 0 & 0 & 0 & 120 & 0 & 120 \\
\hline & alah Persentase & 0 & 0 & 0 & 0 & $100 \%$ & 0 & $100 \%$ \\
\hline
\end{tabular}

Sebagian besar antibiotik profilaksis pada pasien bedah sesar di RSUD Wahab Sjahranie Samarinda Tahun 2014 tergolong kurang tepat menurut kriteria Gyssens yaitu karena kebanyakan tergolong kedalam kategori IV dikarenakan ada alternatif lain yang lebih efektif. Alternatif antibiotik yang lebih efektif ialah cefazolin, karena sefazolin adalah antibiotik sefalosporin generasi pertama yang menjadi first line atau yang direkomendasikan dalam beberapa kasus pembedahan.

\section{KESIMPULAN}

Pasien bedah sesar terbanyak ialah pada usia rentang 20-35 tahun. Penggunaan antibiotik profilaksis pasien bedah sesar di RSUD Abdul Wahab Sjahranie Samarinda berdasarkan jenis antibiotik yang digunakan ialah antibiotik sefalosporin generasi ketiga yaitu sefotaksim sebesar 100\%. Hasil analisis kualitas penggunaan antibiotik profilaksis pasien bedah sesar di RSUD Abdul Wahab Sjahranie Samarinda dengan menggunakan kriteria metode Gyssens menunjukkan penggunaan antibiotik profilaksis yang kurang tepat kategori IV ialah 100\%.

\section{DAFTAR PUSTAKA}

[1] Eniyanti. 2013. Asuhan Kebidanan Pada Persalinan Patologi. Pustaka Pelajar: Yogyakarta.

[2] World Health Organization. 2005. World for Patient Safety.

[3] Departemen Kesehatan RI. 2010. Buku Acuan Persalinan Normal. DepKes RI. Jakarta

[4] Veibymiaty, Sumelung. 2014. Faktor-faktor Yang Berperan Meningkatnya Angka Kejadian Sectio Cesarea Di Rumah Sakit Umum Daerah Liun Kendage Tahuna. Jurnal Keperawatan Vol. 02 No. 01

[5] Manuaba, I.B. 1998. Operasi Kebidanan Kandungan Dan Keluarga Berencana Untuk Dokter Umum. EGC: Jakarta

[6] Desye Nurmalita Tanam. 2011. Tinjauan Penggunaan Antibiotik Pada Pasien Seksio Sesarea Di BLU RSUP Prof Dr. R.D.Kandaou Manado. Jurnal FMIPA UNSRAT

[7] Hidajat, Nucki N. 2009. Pencegahan Infeksi Luka Operasi. Fakultas Kedokteran Universitas Padjajaran: Bandung 